\title{
Tabaco: a construção das políticas de controle sobre seu consumo no Brasil
}

\section{Tobacco: the construction of policies for control of its consumption in Brazil}

\author{
Ivan Farias Barreto
}

Doutorando em Psicologia, Universidade Federal do Rio Grande do Norte; pesquisador, Grupo Interdisciplinar de Estudo sobre Substâncias Psicoativas. Natal - RN - Brasil

ifbarreto@hotmail.com
BARRETO, Ivan Farias. Tabaco: a construção das políticas de controle sobre seu consumo no Brasil. História, Ciências, Saúde - Manguinhos, Rio de Janeiro, v.25, n.3, jul.-set. 2018, p.797-815.

\section{Resumo}

O Brasil se destaca mundialmente na redução do tabagismo devido a suas eficazes políticas de controle. $\mathrm{O}$ artigo analisa, por meio de revisão narrativa, a natureza das discussões científicas que embasaram essas políticas públicas, por meio de perspectivas históricas, sociais, sanitárias e econômicas. Ressalta que as medidas associadas a essas questões têm sido marcadas por disputas de interesses entre as indústrias fumageiras e organizações de saúde. Explora temas ligados a publicidade, redução de danos, políticas tributárias e ações de proteção a não fumantes. Aponta para novas determinações sobre a publicidade de tabaco e sugere, por análise comparativa, veto à propaganda de bebidas alcoólicas no país.

Palavras-chave: tabaco; políticas públicas; campanhas de saúde.

\section{Abstract}

Brazil is a country that stands out worldwide in the reduction of smoking due to its effective control policies. By means of a narrative review, the article analyzes the nature of the scientific discussions that underpin these public policies from historical, social, health and economic perspectives. The fact that the measures associated with these issues have been marked by conflicts of interest between the tobacco industry and health organizations is highlighted. Themes related to advertising, harm reduction, tax policies and actions to protect nonsmokers are scrutinized. New stipulations on tobacco advertising are examined and, by comparative analysis, a veto on the advertising of alcoholic beverages in the country is suggested.

Keywords: tobacco; public policy; health campaigns. 
$\mathrm{O}$ tabagismo é considerado a maior causa de morte evitável do mundo e responsável por provocar diretamente mais de cinquenta doenças. No século XX, o cigarro teria matado mais de cem milhões de pessoas e, se nada for feito, será responsável pela morte de mais um bilhão de pessoas no século XXI (WHO, 2008). A divulgação dessas e outras informações, decorrentes de pesquisas realizadas principalmente a partir da segunda metade do século XX, somada à publicação de documentos secretos da indústria fumageira na década de 1990, tem impulsionado mudanças transnacionais, especialmente no campo das políticas públicas.

Várias medidas têm sido adotadas globalmente, inclusive no Brasil, país destacado pelos êxitos logrados na redução do consumo de tabaco. Dessa forma, procura-se aqui responder como foram construídos os mecanismos de controle sobre o uso de tabaco no Brasil e quais os desafios encontrados na gestão dessas práticas na atualidade.

Para alcançar esses resultados, privilegiou-se na estratégia metodológica a busca de informações em livros, artigos científicos, documentos jurídicos, trabalhos acadêmicos e relatórios de entidades relevantes, principalmente por meio do Portal de Periódicos da Capes e do Google Acadêmico. As palavras-chave mais utilizadas na procura desses materiais foram "tabaco", "tabagismo", "fumo" e "cigarro", nas línguas portuguesa, inglesa e espanhola, privilegiando as produções que se aproximavam das ciências sociais, saúde coletiva e do campo interdisciplinar.

Nessa revisão narrativa serão apresentadas as políticas de controle sobre a publicidade do tabaco, seus impactos sobre o comportamento de fumantes, além de problematizadas as estratégias de redução de danos e proporcionada uma análise comparativa com anúncios de bebidas alcoólicas no país. Abordam-se também as políticas tributárias e suas relações com o consumo de produtos fumígenos. Por fim, discutem-se as políticas de proteção a não fumantes, considerando questões envolvendo a indústria fumageira e o fumo passivo.

\section{A elaboração do discurso científico e as políticas de regulação do tabaco}

Um dos mais antigos registros associando o uso de tabaco a prejuízos à saúde humana data de 1761, quando o médico londrino John Hill correlacionou tumores no nariz ao consumo de rapé (Carvalho, 2001). Em 1798, o médico estadunidense Benjamin Rush publicou sobre os riscos do tabaco para a saúde, apresentando relatos de acidente vascular cerebral, epilepsia, câncer nos lábios, morte súbita por uso excessivo, entre outros (Rosemberg, 1987; Rush, 1798). Em 1859, o clínico francês Bouisson advertiu sobre os efeitos nocivos do fumo em um estudo com 68 clientes do Hospital Montpellier que sofriam de câncer dos lábios, da mucosa bucal e da língua, dos quais 66 fumavam cachimbo (Rosemberg, 1987).

Na terceira década do século XX, outros estudos sobre os malefícios do tabaco, nos EUA e na Inglaterra, geraram grande preocupação para a comunidade médico-científica da época. Lombard e Doering (1928) investigaram 217 pessoas portadoras de câncer e número similar em um grupo de controle, concluindo que fumantes pesados têm maior probabilidade de desenvolver a doença. Uma pesquisa divulgada em 1938 e realizada com 6.813 homens, sendo 2.094 não fumantes, 2.814 fumantes moderados e 1.905 fumantes pesados, concluiu que fumar tabaco estava estatisticamente associado a um prejuízo na expectativa de vida e 
que o grau do dano crescia à medida que a quantidade de cigarros consumidos aumentava (Pearl, 1938). Para Carvalho (2001), estudos como esse viriam a ser modelos ao longo do século XX, ao estabelecer relação entre mortes por câncer e variáveis que incluíam idade, renda, alimentação e fumo.

Por volta da segunda metade do século XX, a indústria fumageira havia consolidado as principais marcas de cigarros no mercado internacional, apesar de uma forte e crescente pressão de entidades científicas que criticavam a veiculação de ideias que transmitiam ao público a imagem de um produto seguro para o consumo. Como resposta, as empresas produtoras de tabaco defenderam a inexistência de pesquisas conclusivas capazes de associar rigorosamente, por exemplo, câncer de pulmão ao tabagismo, ao tempo que manipulavam a opinião pública com o lançamento de cigarros com baixos teores de nicotina ou anúncios que destacavam o caráter light ou suave de seus produtos (Rosemberg, 1987; Carvalho, 2001; Boeira, 2002; Tapia, s.d.).

A fim de amenizar as sucessivas críticas, a indústria fumageira adicionou na década de 1950 os filtros nos cigarros, sugerindo que os consumidores poderiam continuar usando seus produtos de forma segura. A introdução desse dispositivo no Brasil teve ampla aceitação porque o público acreditou estar protegido dos malefícios do tabaco. Em 1977, os cigarros com filtro chegavam a 33\%, atingindo 96\% em 1979 (Rosemberg, 1987).

Matthew Myers, importante personalidade na luta contra o tabagismo e presidente do "Campaign for Tobacco-Free Kids", considera que, provavelmente, uma das mentiras mais devastadoras na história do mundo dos negócios tenha sido a veiculação da ideia de que fumar não causa enfermidades e de que a indústria tabaqueira não focou a publicidade em crianças e adolescentes (Sex, lies..., 2011).

O cigarro tornou-se símbolo de rebeldia, de autonomia e de sucesso. A partir da década de 1950, passou a fazer parte das produções cinematográficas, e o cinema, assim como a publicidade, sem dúvida foi o grande responsável pela propagação do hábito de fumar. Belos astros e estrelas de Hollywood apareciam fumando, atribuindo glamour ao hábito e conquistando uma multidão de imitadores (Rezende Júnior, 2013, p.7).

Por outro lado, cada vez mais pesquisas apontavam a correlação entre o fumo e problemas de saúde, a exemplo da que foi realizada em 1953 pelo médico judeu e alemão Ernst Wynder e seus colaboradores, que experimentaram pincelar o dorso de 81 ratos com alcatrão obtido da condensação da fumaça de cigarros de uma marca popular. Cada rato recebeu, três vezes por semana, quarenta gramas de uma solução de alcatrão e acetona após ter o dorso raspado com barbeador. Dos 62 ratos que sobreviveram após um ano, 58\% desenvolveram câncer. Ao final de vinte meses, 53\% dos ratos do grupo de controle estavam vivos, contra 9,8\% dos que foram pintados com alcatrão (Wynder, Graham, Croninger, 1953).

Essa foi a primeira vez que um experimento de laboratório comprovou o efeito cancerígeno do fumo, tendo uma repercussão negativa para a indústria, resultando numa redução de 10\% do consumo de cigarros em 1953 e 1954. Oito meses antes dessa investigação, Claude Teague, então pesquisador da R.J. Reynolds, afirmou que estudos clínicos tenderiam a confirmar a relação entre o uso prolongado de tabaco e a incidência de câncer de pulmão, e apontou o benzopireno e N-benzopireno como substâncias cancerígenas encontradas nesses produtos (Carvalho, 2001). 
A indústria entrou em pânico. Sua primeira providência foi contratar uma das maiores empresas de relações públicas dos EUA, a Hill and Knowlton, para tentar neutralizar a repercussão dos ratos pintados com nicotina. Em janeiro de 1954, a resposta da indústria circulou num anúncio de página inteira, publicado em 448 jornais americanos. Sob o título 'Uma declaração franca para os fumantes', o anúncio era categórico nas afirmações: não havia provas científicas de que cigarro causasse câncer; os bioestatísticos poderiam apontar como causa qualquer outro fator ligado à vida moderna, como a poluição de carros e fábricas ou a alimentação industrializada. 'Acreditamos que nossos produtos não fazem mal à saúde', dizia o texto, assinado pelo recém-criado Comitê de Pesquisas da Indústria do Tabaco. Ao final do anúncio, o comitê fazia uma promessa: alardeava que a indústria 'aceitava como responsabilidade básica o interesse pela saúde das pessoas, acima de todas as outras considerações de nosso negócio' (Carvalho, 2001, p.15-16).

A essa altura, a indústria do tabaco já tinha conhecimento de que o consumo de cigarro aumentava a incidência de câncer de pulmão. Essa informação foi baseada em mais de 150 mil documentos secretos da indústria fumageira entregues para análise e que só viriam a se tornar públicos em 1994, após ação judicial movida pelos EUA contra a British American Tobacco e a Philip Morris.

Os documentos revelam o conhecimento da indústria do fumo a respeito dos prejuízos que a exposição à fumaça do fumo traz à saúde, bem como os esforços desenvolvidos pela indústria para impedir que as medidas para garantir ambientes interiores limpos não fossem amplamente adotadas. Discutem-se o desenvolvimento de marcas de cigarro, como os ingredientes são manipulados para alcançar diferentes objetivos e as estratégias de comercialização para atingir o maior número de pessoas possível, fumantes e não fumantes. Os documentos também contêm informações importantes sobre o conhecimento e envolvimento da indústria do fumo no contrabando de cigarros e as avaliações da posição das outras empresas no mercado mundial (Brasil, 2004, p.45).

Em 1954, pouco depois de a Philip Morris Companies ter usado bebês em anúncios com finalidade de endossar as escolhas dos pais a consumir o produto, a marca ressurgiu respaldada no mito do cowboy americano. ${ }^{1}$ Demonstrou-se com isso o apelo para a classe trabalhadora masculina, pelas ideias de virilidade e liberdade transmitidas nos anúncios publicitários (Pantani, Pinsky, Monteiro, 2011).

O cigarro talvez tenha conquistado o mundo não por seus efeitos fisiológicos, mas pelo simbolismo que carrega.

Ele é o mais ocidental dos símbolos da passagem da infância para um mundo mais autônomo. Não é à toa que o consumo de cigarro entre adolescentes cresce mesmo em países onde o uso entre adultos está em queda (Carvalho, 2001, p.61).

Mais uma vez, o desenvolvimento de pesquisas confrontava os interesses da indústria fumageira. Ainda em 1954, um estudo epidemiológico realizado por mais de quatro mil médicos britânicos demonstrou mais uma irrefutável associação estatística entre o consumo de tabaco e o câncer de pulmão (Monteverde, Magaña, 2006). Nesse mesmo ano, a publicação de uma investigação realizada por Hammond e Horn nos EUA durante 44 meses, com 187.783 homens, sobre o hábito de fumar, estabeleceu correlação com taxas de mortalidade (Rosemberg citado em Spink et al., 2009). 
A divulgação desses estudos contribuiu para o fortalecimento do movimento antitabagista nos EUA, motivando empresas multinacionais tabageiras a intensificar suas atuações nos países em desenvolvimento, prevendo as dificuldades desses países em elaborar rigorosas legislações para o controle do tabaco (Teixeira, Jaques, 2011). Mirando crianças e adolescentes, a indústria fumageira investiu fortemente na publicidade, expandindo seus negócios em países subdesenvolvidos ou em desenvolvimento. Um executivo da Philip Morris escreveria em 1957: "atingir os jovens pode ser mais eficiente embora o custo de atingi-los seja mais alto, porque os jovens estão dispostos a experimentar, influenciam mais outras pessoas na mesma faixa etária do que em qualquer outra época da vida e são muito mais leais à marca inicial" (Sayginsoy citado em Brasil, 2004, p.51).

Além disso, desde o início dos anos 1960 a indústria tinha conhecimento de que a nicotina era uma substância que causava dependência, sendo relatadas nos arquivos secretos as estratégias de inclusão de produtos químicos para aumentar o grau de adição dos usuários, além de técnicas de manipulação genética de níveis de nicotina. Não seria insensato supor que os governos também estivessem cientes de tais informações, recolhendo por muitos anos grandes somas financeiras provenientes dos tributos sobre o tabaco.

Em contrapartida, a retomada da visão condenatória forte e expressiva sobre o tabaco foi traçada pela Organização Mundial de Saúde (OMS) nos EUA, a partir da década de 1960. Esse contexto histórico aponta para a ampliação e intervenção crescente do discurso médicocientífico na sociedade, por meio de investimentos progressivos na capacidade tecnológica de pesquisa, proporcionando discurso de neutralidade (Gonçalves, 2012). Ademais, o primeiro informe do Surgeon General dos EUA, lançado em 1964, estimulou o desenvolvimento exponencial de pesquisas sobre o tabagismo como indutor de enfermidades em todos os órgãos e sistemas do corpo humano (Monteverde, Magaña, 2006).

O cigarro começou a deixar de ser apenas cigarro em 1964. A mola propulsora da metamorfose foi um relatório de 387 páginas do Ministério da Saúde dos EUA, considerado hoje um marco histórico na saúde pública. Pela primeira vez, um documento oficial americano reconhecia o que os cientistas estavam cansados de saber - que o cigarro causa câncer de pulmão ... um grupo do Ministério da Saúde dos EUA examinou 30 mil textos científicos sobre fumo e, sob o critério da absoluta segurança científica, selecionou 7 mil, que serviram de base para as conclusões (Carvalho, 2001, p.44-45).

No Brasil, de 1964 até o final da década, entraram em pauta no Congresso Nacional diversas iniciativas a fim de coibir a propaganda de tabaco, criar impostos para combater o câncer, imprimir advertências sobre riscos à saúde nos maços de cigarros e até proibir a venda para menores de 18 anos. Seja por conta da pressão da indústria fumageira, da dita desinformação ou da corrupção dos políticos brasileiros, todos esses projetos foram arquivados (Teixeira, Jaques, 2011).

Mas as investigações científicas seguiam a todo vapor. Em 1966, Hammond e Horn publicaram uma pesquisa correlacionando tabagismo e índices de mortalidade envolvendo um milhão de pessoas, levando os EUA a aprovar uma lei impondo mensagem de alerta nos maços de cigarro. Por ocasião da publicação desses relatórios, trinta milhões de estadunidenses deixaram de fumar, fazendo com que a indústria fumageira sofresse um inesperado prejuízo (Rosemberg citado em Spink et al., 2009). 
Somente na década de 1970 o tabagismo surgiu como tema em reuniões mundiais. Diante das evidências, a OMS preparou um relatório intitulado "O hábito de fumar e a saúde", apresentado na $23^{\text {a }}$ Assembleia Mundial de Saúde, conseguindo aprovação para instituir globalmente estratégias de controle sobre o tabagismo (Spink et al., 2009).

A divulgação dessas informações fortaleceu as campanhas antitabagistas, até então muito discutidas sob perspectivas morais e religiosas. Entretanto, tais publicações tiveram pouco impacto no Brasil durante a década de 1970, demonstrando que o discurso científico não estava afinado com os interesses econômicos, sociais e sanitários da época.

Em plena ditadura militar, quando vigorava o liberalismo econômico, e as noções de prevenção e mesmo de saúde pública estavam eclipsadas pela medicina previdenciária de caráter curativo, ... projetos que, além de fugirem às diretrizes governamentais para a saúde colocavam em xeque interesses de grandes forças econômicas, não tinham como sair do papel. Além disso, naquele período, a questão do tabagismo ainda era defendida, principalmente por grupos que a viam sob um viés moral. De início, os médicos a eles se alinharam para fortalecer suas posições; no entanto, o discurso científico ainda não contava com o consenso moral necessário para tornar-se hegemônico. Assim, o tabagismo continuou crescendo e as propagandas de cigarros continuavam vendendo a imagem do ato de fumar, associada ao sucesso, charme, elegância e virilidade (Teixeira, Jaques, 2011, p.297).

Enquanto as políticas de controle sobre o tabaco não eram aprovadas no Brasil, o consumo e a produção aumentavam vertiginosamente. A partir dos anos 1970, grandes multinacionais se instalaram na região do Vale do Rio Pardo (RS), fortalecendo-se em razão da agricultura familiar, mão de obra barata e ao bloqueio comercial do atual Zimbábue, que na época foi o maior exportador de fumo para a Europa (Brasil, 2004).

A produção brasileira de fumo atingiu, em 1975, 250 mil toneladas, subindo em 1981 e 1985, respectivamente, a 315 mil e 411 mil toneladas, significando um aumento de $64 \%$ em dez anos (Rosemberg, 1987). Entre 1970 e 1986, a venda de cigarros no mercado interno cresceu 132\% (Brasil citado em Romero, Silva, 2011).

O movimento de resistência à expansão do tabagismo no Brasil tomou novo fôlego em março de 1979, destacando-se o protagonismo baiano por meio da Carta de Salvador, escrita em um seminário sobre o tema e promovido pelo Instituto Brasileiro para Investigação do Tórax. O documento O tabagismo: um novo desafio criticava as receitas cada vez maiores da indústria de tabaco em detrimento da saúde coletiva e do meio ambiente. No propósito de reduzir o consumo e evitar a iniciação ao fumo, foram lançados 13 objetivos: (1) acentuar a importância de uma boa saúde; (2) defender o direito dos não fumantes; (3) reduzir progressivamente o consumo per capita; (4) baixar o número de fumantes; (5) esclarecer a população sobre a nocividade do tabaco; (6) restringir a produção de cigarros; (7) taxar progressivamente os cigarros; (8) frear a propaganda de cigarros; (9) proteger crianças e gestantes do convívio de fumantes; (10) baixar no cigarro o teor de nicotina, alcatrão e monóxido de carbono; (11) interditar o uso de fumo nas instituições de saúde e educação; (12) proibir a venda de cigarros a menores de 18 anos; (13) criar um comitê nacional e um secretariado permanente para o controle do tabaco (Rosemberg, 1987). 
Em julho de 1979, por iniciativa da Associação Brasileira de Cancerologia, reuniram-se em São Paulo 45 representantes de entidades médico-científicas, órgãos públicos, entidades religiosas e de interesses sociais. Focando crianças, jovens e gestantes, sugeriu-se uma campanha educativa, dando origem ao Programa Nacional Contra o Fumo, que enfatizava informações sobre os riscos do tabagismo, direitos dos não fumantes, além de controle da publicidade, estratégias de restrição do fumo em determinados espaços, aumento de impostos sobre produtos fumígenos e sugestão de incentivos fiscais que estimulassem a substituição das lavouras (Mirra et al., 2009; Teixeira, Jaques, 2011).

Iniciativas governamentais também fizeram história no controle do tabagismo, a exemplo da Secretaria Estadual de Saúde do Paraná, que oficializou em 1979 uma resolução implementando ações educativas e informativas sobre o fumo. No Rio Grande do Sul, maior estado fumicultor, foi definido em 1980 o Programa Estadual de Combate ao Fumo (Pan American Health Organization citado em Romero, Silva, 2011; Mirra et al., 2009).

Essas determinações produziram mobilizações políticas suficientes para aprovação da primeira legislação federal antitabagista brasileira, lei n.7.488/86, que instituiu o dia 29 de agosto como o Dia Nacional de Combate ao Fumo, devendo o Ministério da Saúde, na semana anterior a essa data, realizar uma campanha alertando a população para os malefícios advindos do tabagismo (Brasil, 12 jun. 1986). Já no marco constitucional de 1988 ficou estabelecido que a propaganda comercial de tabaco deveria estar sujeita a restrições legais, contendo, sempre que necessário, advertências sobre as nocividades decorrentes de seu uso (Brasil, 1988). Em 1989, a resolução n.17 aprovou o regimento interno da Câmara dos Deputados proibindo o fumo no recinto do plenário, e o Ministério da Saúde, por meio do Instituto Nacional de Câncer (Inca), lançou o primeiro, Programa Nacional de Controle do Tabagismo (Brasil, 22 set. 1989).

\section{Políticas de controle sobre a publicidade de tabaco no Brasil}

Estudos com foco na publicidade têm orientado a configuração de políticas sobre o tabaco, incluindo restrições de anúncios em programas de televisão, rádio, jornais, revistas, internet, outdoors etc. A Noruega, pioneira na implantação dessa política, testemunhou o consumo de tabaco diminuir ano após ano a partir de 1975.

As evidências demonstram que a publicidade do tabaco aumenta seu consumo, atingindo principalmente os jovens. O Modelo de Simulação de Políticas SimSmoke aplicado no Brasil estimou que $14 \%$ da redução de 46\% na prevalência de tabagismo, entre 1989 e 2010, poderia ser explicado pelas restrições de publicidade dos produtos de tabaco (Projeto ITC, maio 2013).

O Brasil implementou pela primeira vez restrições à publicidade e à promoção do tabaco em 1988, quando se definiram horários para a veiculação de propagandas na televisão, cinema e teatro, acompanhadas de advertência sanitária ... Em 1990, o governo aprovou uma lei que proíbe a publicidade enganosa e abusiva e, em 1995, recomendou que as emissoras de televisão evitassem transmitir imagens de celebridades fumando ... Em dezembro de 2000, foi implementada uma política abrangente que proibiu a publicidade do tabaco em todas as mídias, exceto no ponto de venda, vetou 
o patrocínio de atividades esportivas e culturais nacionais ou internacionais por marcas de tabaco e também proibiu atividades promocionais, tais como amostras grátis e merchandising. Em uma lei aprovada em 2003, toda a publicidade no interior dos pontos de venda era obrigada a ter em $10 \%$ do seu espaço as mesmas advertências sanitárias ilustradas presentes nas embalagens de cigarro... Em dezembro de 2011, toda a propaganda nos pontos de venda foi proibida, exceto a exibição das embalagens para venda (Projeto ITC, maio 2013, p.7).

Entretanto, as indústrias fumageiras continuaram explorando lacunas nas leis. Quando fotografias de advertência sobre os malefícios do tabaco foram introduzidas nas embalagens de cigarros, os fabricantes chegaram a incluir cartões contendo outras imagens dos mesmos formato e tamanho, de maneira que fosse possível cobrir as mensagens desagradáveis (Brasil, 2004). Outras táticas foram utilizadas, destacando-se as campanhas subliminares dirigidas ao público, compra de opinião de cientistas para gerar controvérsias, financiamento de partidos políticos, contratação de grupos de pressão para atuar na formulação de políticas e uso de grupos e indústrias conexas para influir contra as medidas de restrição ao fumo (Laurenti, 2001).

O Advocacy Institute revela que as estratégias usadas pela indústria do fumo para se opor aos esforços de controle podem ser divididas em dez categorias principais: relações públicas, propaganda e promoção, filantropia, financiamento científico, grupos de frente, intimidação, financiamento político, criação de alianças, lobbying e legislação, e políticas públicas (Brasil, 2004, p.45-46).

Desde 2012, após a proibição da publicidade nos pontos de venda, tem-se observado maior uso de aparatos luminosos nas embalagens - sem as advertências de saúde obrigatórias - e modelos de pacotes atraentes (Projeto ITC, maio 2013). Na Austrália, por exemplo, os maços de cigarros têm sido utilizados para fazer pirâmides, paredes de exibição e outros padrões criativos em tetos e pisos, indicando que, para uma política mais eficiente, recomenda-se a disponibilidade dos cigarros apenas debaixo do balcão, evitando sua exibição publicitária nos pontos de venda (Wakefielf et al., 2002). A exposição de embalagens nos mostruários dos pontos de venda, normalmente localizados ao lado de doces e balas, transmite subliminarmente a crianças e adolescentes a ideia de um produto acessível e inofensivo.

As empresas de tabaco têm um envolvimento histórico com a publicidade nos pontos de venda que, segundo documentos da British American Tobacco (BAT), possuíam quatro propósitos principais: informar o consumidor sobre a presença da marca; promover o reconhecimento daquelas já estabelecidas; despertar o interesse por meios táticos (preço, embalagem etc.); estimular a experimentação e a reincidência de compra. O próprio ato de ter o maço à mão, abri-lo e deixá-lo exposto durante o uso é repetido diversas vezes por muitos consumidores, resultando acidentalmente em uma forma de publicidade (Pantani, Pinsky, Monteiro, 2011).

As autoras ainda lembraram um teste conduzido pelo departamento de pesquisa da Philip Morris, concluindo que os fumantes de cigarros com embalagens vermelhas eram, em sua maioria, homens veteranos leais à marca que não se preocupavam com a saúde nem pretendiam parar de fumar. Já os fumantes de cigarros do tipo suave revelavam ser, em sua maioria, mulheres e pessoas que desejavam parar de fumar (Philip Morris, USA, 1979). 
Considerando que os pacotes de cigarros transmitem ideias e influenciam as decisões de compra, faz sentido pensar na adoção de um desenho genérico a todas as marcas, tornando as embalagens apenas funcionais.

Uma pesquisa brasileira recente apontou a existência de PDVs [pontos de venda] de cigarros em um raio de até um quilômetro de escolas de nível fundamental e médio e faculdades. A frequência com que crianças até 12 anos visitam esses estabelecimentos é de $72 \%$ e para adolescentes entre 12 a 18 anos, de $81 \%$. Em 82\% dos casos, os cigarros encontram-se dispostos em displays e em $84 \%$ são visíveis para as crianças. Além disso, $66 \%$ desses PDVs possuem cartazes de propaganda de cigarros facilmente visíveis (Pantani, Pinsky, Monteiro, 2011, p.68).

Uma medida estipulada pela Agência Nacional de Vigilância Sanitária (Anvisa) por meio da resolução n.14, de 10 de abril de 2015, estabeleceu, a partir de 2016, a obrigatoriedade de advertências sanitárias em produtos fumígenos, de modo a ocupar 30\% da parte inferior da face frontal dos pacotes (Brasil, 13 abr. 2015). Trata-se de uma medida que visa conscientizar e incomodar os consumidores que frequentemente posicionam os maços com a face frontal voltada para cima, escondendo as impactantes mensagens de alerta do Ministério da Saúde.

Observa-se ainda que as políticas de controle do tabaco se preocupam com a divulgação de informações sobre malefícios do fumo, mas não orientam para um uso menos danoso da substância. Pode-se questionar a não inclusão de mensagens voltadas para a redução de danos, considerando a existência de pessoas que não conseguem ou não desejam parar de fumar. Há, aí, a noção generalizada de que não existe redução de danos para o consumo de tabaco, restringindo o alcance de políticas públicas ligadas diretamente à prevenção terciária e à promoção de saúde. A noção centrada na abstinência não é o único caminho, pois não considera distintos modos de uso.

Nesse caso, as orientações poderiam incluir a redução do consumo diário e diminuição do número e profundidade de tragadas, pois o risco dos fumantes é proporcional à intensidade da inalação. Também se deve evitar manter o cigarro na boca entre as tragadas, não reacender aqueles que já foram apagados e dispensar o último terço do cigarro, pois a concentração de alcatrão e nicotina aumenta progressivamente durante o consumo, atingindo níveis altos na última terça parte (Rosemberg, 1987).

Outra estratégia para redução de danos tem sido estruturada em torno dos cigarros eletrônicos. Embora seu comécio, importação e propaganda estejam proibidos desde 2009, pela resolucão n.46 da Agência Nacional de Vigilância Sanitária, pesquisas têm indicado que esses dispositivos podem causar menos malefícios à saúde se comparados aos cigarros combustíveis, além de apresentar eficácia igual ou superior às terapias de reposição de nicotina, quando utilizados em contextos de cuidado (Barreto, 2018). Para refletir sobre a redução de danos como paradigma orientador da política de drogas, recorre-se à literatura socioantropológica, que traz importantes considerações:

Partimos do posicionamento de que a abordagem mais indicada para a questão das drogas seja aquela que prioriza a redução dos danos decorrentes desse uso que acreditamos ser inevitável para a maioria das pessoas. Entendemos que o bom senso 
dita que a redução dos danos, concebidos de forma ampla, incluindo aspectos sociais, culturais, políticos econômicos e sanitários, deva ser o objetivo principal a ser atingido por uma política sobre drogas. Cremos que os controles da oferta e do consumo devam ser concebidos somente como possíveis estratégias pontuais, a ser aplicados nos casos em que seja demonstrada de maneira científica a real necessidade de se restringir dessa forma a liberdade do conjunto dos membros da sociedade (MacRae, Gorgulho, set.-out. 2003, p.372).

Ressalta-se que o afastamento de perspectivas puramente biomédicas para compreensão do fenômeno das drogas também tem sido pontuado por outros pesquisadores. Após estudo com usuários de heroína, o médico estadunidense Norman Zinberg (1984) afirmou que a relação da pessoa com a droga pode variar de acordo com o efeito farmacológico da substância, bem como o contexto físico e social, além da atitude e personalidade do sujeito que faz uso, lançando uma importante teoria de base biopsicossocial para compreensão dos motivos envolvidos no uso de drogas e no modo como afetam seus consumidores.

Em uma pesquisa com usuários de maconha, o sociólogo estadunidense Howard Becker (1973) abordou os controles sociais e suas influências no consumo de substâncias psicoativas. Em sua tese de doutorado sobre usuários de heroína e cocaína em Roterdã, o psicólogo holandês Jean Paul Grund (1993) considerou a disponibilidade da droga e a estrutura de vida como determinantes essenciais nos processos de autorregulação do uso de drogas. Os cientistas sociais franceses Castel e Coppel (1991) afirmaram que os controles societais e as políticas públicas de Estado são insuficientes no processo de disciplinarização do consumo de psicoativos devido a suas construções parciais, que desconsideram a totalidade dos fenômenos e os relacionam apenas à psicopatologia.

Esses autores dialogam além das práticas institucionalizadas, apontando também para os controles sociais informais, vistos como dispositivos para regulação do consumo dessas substâncias. Nesse sentido, Foucault (2013) considera que o dispositivo - como rede heterogênea de discursos organizacionais e científicos com função de responder a uma urgência histórica - está sempre inscrito em um jogo de poder, frequentemente representado sob forma jurídica. A constituição do dispositivo médico-legal, no caso do consumo de tabaco, evidencia a multiplicação dos controles, intervenções de tipo penal ou não (sanções formais e informais), sobre condutas ou comportamentos ditos adequados (Foucault, 2013).

Se o Estado tem alguma preocupação com a redução do número de fumantes e dos danos associados é devido a um lucro econômico e utilitarismo político. De certo ponto de vista, o interesse pelos fumantes e suas vidas é secundário, priorizando os mecanismos de controle, punição e poder que aí se encontram. O exercício do biopoder pelo Ministério da Saúde, visto como agência que administra a saúde dos corpos, embasou normas coletivas com finalidade de controlar o corpo social por meio de instituições aliadas às tecnologias de poder, executadas por meio de discursos que previnem, classificam, tratam e regulamentam as políticas de controle sobre o tabaco e outras drogas (Foucault, 1993, 2013). 


\section{Observações envolvendo a publicidade de tabaco e bebidas alcoólicas}

A publicidade do tabaco também permite discutir, via análise comparativa, questões envolvendo anúncios de produtos alcoólicos. Importante salientar que a lei n.9.294/96, que regula a publicidade de álcool e tabaco, considera bebidas alcoólicas aquelas com teor de álcool superior a 13 graus Gay Lussac (Brasil, 16 jul. 1996). Essa determinação exclui várias restrições publicitárias a drogas como a cerveja, consumida por 59,6\% dos bebedores brasileiros (WHO, 2014).

Mais recentemente, a lei n.11.705/2008 estabeleceu punições mais severas ao condutor que dirigir sob influência de álcool, além de definir bebidas alcoólicas aquelas com teor de álcool superior a 0,5 grau Gay Lussac (Brasil, 20 jun. 2008). Ou seja, há dois pesos e duas medidas jurídicas em relação ao conceito de bebidas alcoólicas, sendo muito mais branda para a publicidade, revelando a pressão da indústria sobre a mídia, políticos e poderes públicos, a fim de limitar o controle formal do governo. Sabe-se, no entanto, que o estímulo ao uso dessas substâncias tem responsabilidade pelos prejuízos inestimáveis à sociedade brasileira.

O álcool pode causar mais de duzentas doenças e condições de lesões, destacando-se dependência física/psíquica, cirrose, câncer e acidentes. Em 2012, 5,9\% das mortes e 5,1\% das doenças e lesões em todo o mundo foram atribuídas ao consumo de álcool. No Brasil, $18 \%$ e 5,2\% dos acidentes de trânsito entre homens e mulheres, respectivamente, tiveram relação com o consumo de álcool. Estima-se ainda que a prevalência de distúrbios do uso de álcool na população brasileira em 2010 foi de 8,2\% em homens e 3,2\% em mulheres (WHO, 2014).

Uma análise relacionada ao consumo de álcool entre 2007 e 2009, em 16 países da América Latina, afirmou que 79.456 mortes anuais poderiam ter sido evitadas se não houvesse ingestão excessiva da substância. No Brasil, homens têm duas vezes mais chances de fazer uso da droga regularmente e são três vezes mais propensos a beber em excesso. $\mathrm{O}$ país apareceu em quinto lugar com relação ao número de mortes por ano, sendo 12,2 para 100 mil habitantes (Gawryszewski, Monteiro, 2014).

Pesquisa realizada com base no Segundo Levantamento Domiciliar sobre o Uso de Drogas Psicotrópicas apontou que em 33,5\% dos domicílios foi relatado algum tipo de violência, estando os agressores sob efeito de álcool em 17\% desses casos (Fonseca et al., 2009). Em outro estudo, realizado em 27 municípios de São Paulo, foi revelado que nos domicílios pesquisados 52,7\% das mulheres que mencionaram situação de violência declararam estar o(a) autor(a) alcoolizado(a) (Noto et al. citado em Vieira et al., 2014).

Dados do Segundo Levantamento Nacional de Álcool e Drogas (Lenad) mostraram que, entre 2006 e 2012, houve aumento significativo na frequência do consumo daqueles que já faziam uso de bebidas alcoólicas. Em 2006, 54\% dos homens consumiram álcool ao menos uma vez por semana, e, em 2012, a taxa foi de 64\%. Entre as mulheres foi ainda mais significativo, passando de 27\% em 2006 para 38\% em 2012 (Laranjeira et al., 2014). De acordo com o coordenador do estudo, o aumento de mais de $40 \%$ do consumo entre as mulheres pode ser explicado pelo maior número de publicidades voltadas para esse público (Yarak, 10 abr. 2013). 
De modo geral, o que importa depreender de estudos semelhantes a este é que o estímulo ao uso abusivo do álcool tem gerado consequências alarmantes em níveis social e humano, e que, no entanto, a soma desses prejuízos não tem despertado o interesse do poder público nem da sociedade para uma ação direta de enfrentamento destes problemas, como foi feita, por exemplo, em torno da restrição à publicidade do tabaco (Moreira, 2009, p.14).

Com base em Moreira (2009), as críticas direcionadas às propagandas de tabaco podem ser usadas para as bebidas alcoólicas, considerando que a indústria fumageira lançou mão de estratégias de publicidade semelhantes àquelas atualmente utilizadas pelas indústrias cervejeiras. Vale lembrar que, por muitos anos, a indústria fumageira do Brasil associou a sua imagem ao esporte, como o automobilismo, atividades desportivas aéreas e aquáticas, além de escalada, motociclismo, entre outros. Da mesma forma, gigantes de bebidas alcoólicas têm sistematicamente patrocinado eventos esportivos, como o futebol, chegando na década de 2010 a fechar contratos de exclusividade para a venda de seus produtos em estádios e a comprar os direitos sobre a propriedade dos nomes desses estabelecimentos, a exemplo da Arena Fonte Nova, em Salvador, e da Arena Pernambuco, na região metropolitana do Recife. Tais situações são dignas de repúdio por conta da associação inadequada entre o esporte e uma substância que, comprovadamente, provoca graves danos à saúde e à coletividade.

Enquanto isso, a publicidade dos artigos alcoólicos apresenta estilos de vida diferenciados a cada bebida ou público-alvo. A cerveja, por exemplo, prevalece voltada para todas as classes e idades, com apelos frequentes que vão desde a virilidade ao erotismo de atrizes que mimetizam atributos de refrescância, relaxamento e sedução nos comerciais televisivos (Trad, 2004). Tais estratégias, de forte cunho emocional, são muito bem conhecidas e foram largamente utilizadas pela indústria fumageira na manutenção e captação de novos consumidores, principalmente os jovens.

Ao contrário do que ocorre com relação às embalagens de cigarros/tabaco e seus respectivos alertas aos danos, os rótulos de produtos alcoólicos trazem apenas uma recomendação de pouco impacto, que soa quase como um lema publicitário visando incentivar o uso: "aprecie com moderação". O mesmo ocorre na mídia televisiva por meio do "beba com moderação", muitas vezes pronunciado tão rapidamente que se torna quase ininteligível. Recomenda-se, portanto, vetar a publicidade de bebidas alcoólicas e adotar mensagens de alerta nos rótulos desses produtos, a exemplo: “O Ministério da Saúde adverte: o consumo de álcool pode causar doenças como câncer e cirrose hepática", "Álcool é droga e pode causar dependência física e psíquica", "Consumir bebidas alcoólicas durante a gravidez causa má formação no bebê". Outra opção seria a inclusão de orientações visando à redução dos danos, como por exemplo: "Alimente-se e hidrate-se durante o consumo de álcool", "Evite conduzir carros, motos ou embarcações sob efeito de álcool", "Evite consumir álcool juntamente com outras substâncias psicoativas".

\section{Políticas tributárias sobre o consumo de tabaco}

Políticas tributárias austeras para produtos fumígenos têm desempenhado papel fundamental no controle do tabagismo. Essa estratégia tem tido importantes resultados 
para a melhoria da saúde pública, causando a cessação ou diminuição do consumo principalmente entre jovens e pessoas de baixa renda.

Pesquisas apontam que o aumento de $10 \%$ no preço do cigarro resulta numa diminuição de seu consumo em $2,5 \%$ a $5 \%$, sendo adolescentes e adultos jovens os mais sensíveis a essa medida, diminuindo suas demandas duas ou três vezes mais que adultos. Isso porque os jovens têm menos dinheiro para gastar com tabaco, encontrando-se mais suscetíveis à pressão de seus pares, de modo a reduzir o consumo, além de ser menos adictos que os adultos e mais orientados para o presente (Gilbert, Cornuz, 2003).

um aumento de $10 \%$ no preço dos cigarros reduz o consumo, no curto prazo, em 3-5\% nos países desenvolvidos de renda alta e em $8 \%$ nos países de renda baixa e média ... Aumentar os preços através do aumento dos impostos é considerada a ferramenta mais eficaz no controle do tabagismo. A redução do consumo é maior nos jovens e nos grupos de baixa renda (Townsend, citado em Brasil, 2004, p.38).

O aumento de impostos contribui tanto para os cofres públicos quanto para a saúde coletiva, pois essas receitas podem ajudar no aumento do poder de fiscalização contra a publicidade desses produtos e ampliar os programas de prevenção e educação em saúde. Porém, a indústria fumageira frequentemente alega que essa medida prejudica a economia e a empregabilidade.

A experiência em outros lugares tem demonstrado que os políticos muitas vezes se opõem ao aumento dos impostos sobre o tabaco, argumentando que a diminuição resultante da demanda e vendas custaria ao governo uma receita significativa. Contudo, verificou-se o contrário: ainda que a alta de preço por aumento de impostos resulte numa diminuição do consumo e na venda de cigarros, o consumo baixaria a uma proporção menor ao aumento dos impostos, o que resultaria em um aumento líquido da receita fiscal. Assim, quanto a receitas fiscais, o aumento dos impostos supera as perdas produzidas pela diminuição do consumo (Bonilla, 2012, p.12). ${ }^{2}$

As considerações da indústria fumageira são exageradas, pois o dinheiro gasto em tabaco seria deslocado para outros bens e serviços, gerando novos postos de trabalho em lugar dos que foram perdidos (Jha, Chaloupka, citados em Gilbert, Cornuz, 2003). Uma equipe com trinta profissionais conceituados internacionalmente em disciplinas como economia e epidemiologia concluiu que, na maioria dos países, o controle do tabaco não levaria a uma perda líquida de postos de trabalho, podendo em muitas circunstâncias gerar mais empregos (Hu, Mao, 2002). Como se pode constatar a seguir, as indústrias fumageiras reconhecem há anos que o aumento de impostos é eficaz na redução do consumo de cigarros.

Em 1995 um documento interno da empresa Philip Morris International (PM) advertia com 'alarde' que os impostos 'deprimem de maneira severa' o volume de vendas de tabaco. E, por sua vez, a empresa British American Tobacco (BAT) havia assinalado dois anos antes que 'o aumento dos impostos, que reduzem o consumo, pode significar a destruição da vitalidade da indústria do tabaco' (Armendares, Shigematsu, 2006, p.s168; destaques no original).

Outro argumento utilizado pela indústria do tabaco é que o aumento de impostos elevaria o contrabando de cigarros. No entanto, essa ideia parece superestimada, pois, ainda 
que houvesse um pequeno aumento nas taxas de contrabando, os benefícios econômicos e sanitários compensariam os esforços.

há evidências nos documentos da indústria de que as próprias empresas têm estado envolvidas no contrabando e estão cientes de que, algumas vezes, as remessas desses produtos destinam-se ao mercado ilícito. A indústria do fumo também continua a argumentar que o contrabando resulta de aumento nos impostos, mas estudos do Banco Mundial têm mostrado a falsidade dessa argumentação. Aumentar impostos reduz o consumo, mas não necessariamente aumenta o contrabando (Brasil, 2004, p.54).

A Organização Pan-Americana da Saúde publicou, em 2001, o relatório Profits over people, revelando que um diretor de publicidade da Souza Cruz, no início da década de 1990, planejou comercializar cigarros contrabandeados para competir por uma fatia maior no mercado. Isso porque o contrabando, além de baratear os produtos e estimular um aumento de consumo, motiva as empresas de fumo a pressionar o governo para que diminua os impostos sobre cigarros, promovendo o mito de que tributos mais altos induzem ao contrabando (Brasil, 2004).

O comércio ilegal de cigarros é causado mais pela corrupção do que pelo aumento de preços sobre o tabaco. Recomenda-se que os governos não renunciem aos benefícios da tributação sobre o fumo e que ajam para detectar, impedir e punir o contrabando (Hu, Mao, 2002; Brasil, 2004).

tabagismo é consequência do consumo de um produto comercializado por empresas que historicamente têm tentado apresentar o tabaco como um setor importante da economia, gerador de riquezas e empregos, especialmente para o setor agrícola. No entanto, os custos sociais engendrados pelo consumo do tabaco não compensam os benefícios econômicos trazidos pela sua comercialização (Pantani, Pisnky, Monteiro, 2011, p.61).

O Ministério da Saúde estabelece uma série de sugestões para minimizar os efeitos do contrabando na saúde pública, entre elas: (1) aumentar as penalidades; (2) criar selos/marcas de impostos pagos e encerrar as vendas no duty-free; (3) licenciar os exportadores de cigarros, fabricantes e distribuidores e requerer registros detalhados; (4) exigir um código único de identificação em todos os pacotes de cigarros, a fim de mapear os cigarros contrabandeados; (5) responsabilizar os exportadores de cigarros pelo destino final do produto; (6) destinar mais recursos para detenção e condução de processos; e (7) incentivar a colaboração e comunicação entre funcionários de alfândegas em todo o mundo (Brasil, 2004).

\section{Políticas de proteção a não fumantes}

Quando começaram a surgir pesquisas indicando que a exposição ao tabagismo ambiental colocava a saúde de não fumantes em risco, a indústria do fumo passou a contestar esses resultados. Financiados pela indústria fumageira, uma rede de cientistas e outros consultores passaram a desenvolver estudos pouco rigorosos a fim de provar que o fumo passivo não é prejudicial (Brasil, 2004).

O relatório Profits over people descreve quatro estratégias usadas pelas empresas de tabaco na América Latina e no Caribe para prevenir ações contra o fumo passivo: (1) negar a 
evidência da ligação entre o tabagismo de segunda mão e diversas doenças; (2) situar o tabagismo ambiental como um componente menor da contaminação do ar; (3) promover áreas compartilhadas por fumantes e não fumantes; e (4) viabilizar essas estratégias por meio de supostas "pesquisas independentes". A seguir, trecho encontrado em documentos internos da indústria fumageira mostra a importância atribuída ao sigilo da ligação de cientistas com as empresas de tabaco (Brasil, 2004).

Não posso frisar suficientemente a necessidade absoluta 'de evitar qualquer contato direto' da indústria com os cientistas [os consultores] que participam do programa... Se um cientista do grupo for percebido, por qualquer pessoa, como associado à indústria, então corremos o risco de que o mesmo ocorra, por associação, com o restante do grupo e o esforço todo tornar-se-á sem sentido. Conforme foi explicado anteriormente, todo contato deve ser efetuado através da Convington and Burling (Boyse citado em Brasil, 2004, p.64; destaques no original).

É preciso reconhecer que as medidas legislativas por si só não promovem uma mudança de hábito da população, admitindo-se o caminho da educação como meio eficaz na redução da exposição de crianças e adolescentes à fumaça do tabaco. De acordo com Brasil (16 jul. 1996), a lei federal n.9.294/96 proibia o uso de cigarros ou de qualquer outro produto fumígeno, derivado ou não do tabaco, em recinto coletivo privado ou público, salvo em área destinada a esse fim, devidamente isolada e com arejamento conveniente.

Na forma como foi redigida, a legislação brasileira deu margem para que a indústria do cigarro desenvolvesse no Brasil, como havia feito em outras partes do mundo, programas para manter o fumo socialmente aceito e permissível em todos os ambientes, incentivando a coexistência entre fumantes e não fumantes. A motivação da indústria é a evidência de que áreas $100 \%$ livres da FAT [fumaça ambiental do tabaco] diminuem o consumo de cigarros e, em consequência, os lucros da indústria (Bialous et al., 2010, p.284).

Só mais recentemente, com a aprovação do decreto n.8.262/2014, foi que, definitivamente, proibiu-se o uso de produtos fumígenos, derivados ou não do tabaco, em recinto coletivo fechado. Estabeleceu-se ainda uma nova definição para "recinto coletivo" compreendendo-o como "local público ou privado, acessível ao público em geral ou de uso coletivo, total ou parcialmente fechado em qualquer de seus lados por parede, divisória, teto, toldo ou telhado, de forma permanente ou provisória" (Brasil, 2 jun. 2014).

\section{Considerações finais}

A configuração atual dos dispositivos de controle sobre o tabaco apresenta raízes históricas que marcam interesses políticos e econômicos praticamente em todo o mundo. Destaque para os conflitos de interesses entre as gigantes da indústria fumageira e as organizações de saúde durante praticamente todo o século XX. Ao final desse período, políticas públicas começaram a ser instituídas no Brasil em resposta aos agravos à saúde provocados pelo fumo e comprovados em vários estudos.

No que se refere às estratégias de controle sobre a publicidade, apesar dos avanços, ainda há o que ser feito para diminuir os estímulos apelativos aos consumidores existentes 
e potenciais. Nesse caso, a padronização dos maços de cigarros, a adição de imagens impactantes na parte frontal das embalagens e a restrição quanto à exposição dos produtos nos pontos de venda, de modo que fiquem atrás do balcão e impeçam que crianças e adolescentes tenham acesso visual, parecem ser os maiores desafios na atualidade brasileira.

Por via comparativa, sugere-se que sejam vetadas as propagandas de bebidas alcoólicas no país, evitando o estímulo ao seu consumo. Orienta-se para a inclusão de imagens e mensagens de redução de danos e/ou de impacto nos rótulos das embalagens de produtos alcoólicos, visando conscientizar a população e reduzir os riscos e o consumo prejudicial dessas substâncias.

Recomenda-se a manutenção da política de aumento tributário sobre o tabaco e de proteção ao fumo passivo, medidas eficazes na diminuição do consumo da substância e no cuidado com a saúde coletiva. Constata-se que os êxitos alcançados com a redução do tabagismo no Brasil, principalmente nas últimas décadas, são resultados de uma política de Estado eficiente, que se encontra alinhada com os saberes científicos produzidos.

Diferentemente de outras políticas de drogas, como aquelas voltadas para o álcool e substâncias tornadas ilícitas - frequentemente estruturadas sob vieses lobistas, moralistas ou religiosos -, a política brasileira para controle do tabagismo tem sido organizada em intervenções pontuais e inteligentes, não em ações repressivas, violentas ou persecutórias. Nesse sentido, tem conseguido fazer mais para a população, evidenciando que a cada tempo novos saberes, posturas políticas e padrões de comportamento são ajustados para que a sociedade melhor se adapte ao fenômeno do consumo de drogas, tão antigo quanto a própria humanidade.

\section{AGRADECIMENTOS}

Este trabalho é parte da dissertação de mestrado em antropologia defendida pelo autor em 2015 na Universidade Federal da Bahia, tendo sido adaptado e revisado para publicação nesta revista. O autor agradece as orientações dos professores doutor Edward MacRae e doutora Roca Alencar, bem como o financiamento dessa pesquisa pela Coordenação de Aperfeiçoamento de Pessoal de Nível Superior (Capes).

\section{NOTAS}

${ }^{1}$ A título de curiosidade, David McLean, ator estadunidense que atuava como cowboy nas propagandas de Marlboro, faleceu em 1995 de câncer de pulmão. Um ano depois, sua família moveu ação judicial contra a Philip Morris alegando que a empresa seria a principal responsável por sua morte.

${ }^{2}$ Nessa e nas demais citações de textos em outros idiomas, a tradução é livre.

\section{REFERÊNCIAS}

ARMENDARES, Pedro E; SHIGEMATSU, Luz M.R. Política fiscal y control del tabaco: una oportunidad única para beneficiar a la salud pública y al erario. Salud Pública de México, v.48, supl.2, p.s176-s172. 2006.

BARRETO, Ivan F.

Tabagismo, cigarros eletrônicos e redução de danos: uma revisão narrativa. Revista Ciências em Saúde, v.8, n.1, p.18-23. 2018.

BECKER, Howard.

Outsiders. New York: The Free Press. 1973.

BIALOUS, Stella A. et al.

A resposta da indústria do tabaco à criação de espaços livres de fumo no Brasil. Revista 
Panamericana de Salud Pública, v.27, n.4, p.283290. 2010.

BOEIRA, Sérgio L.

Atrás da cortina de fumaça: tabaco, tabagismo e meio ambiente: estratégias da indústria e dilemas da crítica. Itajaí: Univali. 2002.

BONILLA, Maria C.M.

Economía del tabaco. Acta Médica Costarricense, v.54, n.1, p.8-14. 2012.

BRASIL.

Agência Nacional de Vigilância Sanitária. Resolução RDC n.14, de 10 de abril de 2015. Dispõe sobre a advertência sanitária que deve ocupar 30\% (trinta por cento) da parte inferior da face frontal das embalagens de produtos fumígenos derivados do tabaco. Diário Oficial da União, seção 1, p.48-56. 13 abr. 2015.

BRASIL.

Decreto n.8.262, de 31 de maio de 2014. Altera o decreto n.2.018, de 1 de outubro de 1996, que regulamenta a lei n.9.294, de 15 de julho de 1996. Diário Oficial da União, seção 1, p.1. 2 jun. 2014.

BRASIL.

Lei n.11.705, de 19 de junho de 2008. Altera a lei n.9.503, de 23 de setembro de 1997, que institui o Código de Trânsito Brasileiro, e a lei n.9.294, de 15 de julho de 1996, que dispõe sobre as restrições ao uso e à propaganda de produtos fumígeros, bebidas alcoólicas, medicamentos, terapias e defensivos agrícolas, nos termos do $\S 4^{\circ}$ do art. 220 da Constituição Federal, para inibir o consumo de bebida alcoólica por condutor de veículo automotor, e dá outras providências. Diário Oficial da União, seção 1, p.1. 20 jun. 2008.

BRASIL.

Ministério da Saúde. Organização Panamericana da Saúde. Tabaco e pobreza, um círculo vicioso: a convenção-quadro de controle do tabaco: uma resposta. Brasília: Ministério da Saúde. 2004.

BRASIL.

Lei n.9.294, de 15 de julho de 1996. Dispõe sobre as restrições ao uso e à propaganda de produtos fumígeros, bebidas alcoólicas, medicamentos, terapias e defensivos agrícolas, nos termos do $\S 4^{\circ}$ do art. 220 da Constituição Federal. Diário Oficial da União, seção 1, p.13074. 16 jul. 1996.

BRASIL.

Congresso Nacional. Câmara dos Deputados. Resolução n.17, de 1989. Aprova o Regimento Interno da Câmara dos Deputados. Diário do Congresso Nacional, seção 1, p.3. 22 set. 1989.
BRASIL.

Constituição da República Federativa do Brasil. Brasília: Senado Federal. 1988.

BRASIL.

Lei n.7.488, de 11 de junho de 1986. Institui o "Dia Nacional de Combate ao Fumo". Diário Oficial da União, seção 1, p.8531. 12 jun. 1986.

CARVALHO, Mario C.

O cigarro. São Paulo: Publifolha. (Coleção Folha Explica). 2001.

CASTEL, Robert; COPPEL, Anne.

Les contrôles de la toxicomanie. In: Ehrenberg, Alain (Org.). Individus sous influence: drogues, alcools, médicaments psychotropes. Paris: Esprit. p.237-256. 1991.

FONSECA, Arilton M. et al.

Padrões de violência domiciliar associada ao uso de álcool no Brasil. Revista de Saúde Pública, v.43, n.5, p.743-749. 2009.

FOUCAULT, Michel.

Microfísica do poder. Organização, introdução e revisão técnica: Roberto Machado. São Paulo: Graal. 2013.

FOUCAULT, Michel.

About the begging of hermeneutics of the Self. Political Theory, v.21, n.2, p.198-227. 1993.

GAWRYSZEWSKI, Vilma P.; MONTEIRO, Maristela G.

Mortality from diseases, conditions and injuries where alcohol is a necessary cause in the Americas, 2007-09. Addiction, v.109, n.4, p.550557. 2014.

GILBERT, Allison; CORNUZ, Jacques. Which are the most effective and cost-effective interventions for tobacco control? Copenhagen: WHO Regional Office for Europe. (Health Evidence Network report). Disponível em: $<$ http://www.euro.who.int/document/e82993. pdf>. Acesso em: 24 jul. 2014. 2003.

GONÇALVES, Patrícia da R.

Cigarro: a fumaça da discórdia: uma análise sobre a construção da regulação do consumo de tabaco. Curitiba: Appris. 2012.

GRUND, Jean P.C.

Drug use as a social ritual: functionality, symbolism and determinants of self-regulation. Rotterdam: Instituut voor Verslavingsonderzoek (IVO); Erasmus Universiteit Rotterdam. 1993.

HU, Teh-Wei; MAO, Zhengzhong. Economic analysis of tobacco and options for tobacco control: China case study. (HNP discussion paper; Economics of tobacco control paper, n.3). Washington: World Bank. 2002. 
LARANJEIRA, Ronaldo et al. (Org.).

Levantamento Nacional de Álcool e Drogas, 2. São Paulo: Instituto Nacional de Ciência e Tecnologia para Políticas Públicas de Álcool e Outras Drogas (Inpad); Unifesp. 2014.

\section{LAURENTI, Ruy.}

Tática da indústria do tabaco contra as políticas de saúde pública. Revista da Associação Médica Brasileira, v.47, n.3, p.175-176. 2001.

LOMBARD, Herbert; DOERING, Carl. Cancer studies in Massachusetts, 2: habits, characteristics and environment of individuals with and without cancer. New England Journal of Medicine, v.198, n.10, p.481-487. 1928.

MACRAE, Edward; GORGULHO, Mônica. Redução de danos e tratamento de substituição: posicionamento da Reduc. Jornal Brasileiro de Psiquiatria, v.52, p.371-374. set.-out. 2003.

MIRRA, Antônio P. et al.

Resgate histórico do controle do tabagismo na Faculdade de Saúde Pública da Universidade de São Paulo: um relato de experiência. Saúde e Sociedade, v.18, n.1, p.164-170. 2009.

MONTEVERDE, Horacio R; MAGAÑA,

Alessandro R.

Breves comentarios sobre la historia del tabaco y el tabaquismo. Revista del Instituto Nacional de Enfermedades Respiratorias, v.19, n.4, p.297-300. 2006.

MOREIRA, Luiz M.T.

A influência da mídia no uso abusivo do álcool. Monografia (Graduação em Psicologia) Faculdade Ruy Barbosa, Salvador. 2009.

PANTANI, Daniela; PINKSY, Ilana; MONTEIRO, Anna.

Publicidade de tabaco no ponto de venda. São Paulo: Editora do Autor. 2011.

PEARL, Raymond.

Tobacco smoking and longevity. Science, v.87, n.2.253, p.216-217. 1938.

PHILIP MORRIS, USA.

Smoker's reactions to an ultra light brand extension for Marlboro: a qualitative study. Legacy Tobacco Document Library. Disponível em: <https://www.industrydocumentslibrary. ucsf.edu>. Acesso em: 12 out. 2017. 1979.

PROJETO ITC.

Projeto Internacional de Avaliação das Políticas de Controle de Tabaco. Relatório da Pesquisa ITC Brasil sobre publicidade, promoção e patrocínio de tabaco. [s.l.: s.n.]. Disponível em: <http://actbr. org.br/uploads/arquivo/810_ITC_BRAZIL.pdf $>$. Acesso em: 10 jul. 2018. maio 2013.
REZENDE JÚNIOR, Gildo Costa.

Impacto das campanhas publicitárias contra o tabagismo no comportamento do consumidor. Dissertação (Mestrado em Publicidade e Marketing) - Instituto Politécnico de Lisboa, Lisboa. 2013.

ROMERO, Luiz C.; SILVA, Vera L. da C. 23 anos de controle do tabaco no Brasil: a atualidade do Programa Nacional de Combate ao Fumo de 1988. Revista Brasileira de Cancerologia, v.57, n.3, p.305-314. 2011.

ROSEMBERG, José.

Tabagismo, sério problema de saúde pública. São Paulo: Almed. 1987.

RUSH, Benjamin.

Essays, literary, moral and philosophical. Philadelphia: Thomas and Samuel Bradford. 1798.

SEX, LIES...

Sex, lies and cigarettes. Direção: Jeffrey Plunkett; Alex Simmons. Estados Unidos: Vanguard. 45 $\min .2011$.

SPINK, Mary J.P. et al.

A construção do tabagismo como problema de saúde pública: uma confluência entre interesses políticos e processos de legitimação científica. Interface: Comunicação, Saúde, Educação, v.13, n.29, p.353-365. 2009.

TAPIA, Edmundo.

Tabaco: a guerra do fumo. [s.l.]: Europa Press. s.d.

TEIXEIRA, Luiz A; JAQUES, Tiago A.

Legislação e controle do tabaco no Brasil entre o final do século XX e início do XXI. Revista Brasileira de Cancerologia, v.57, n.3, p.295-304. 2011.

TRAD, Sérgio.

Mídia e drogas: confrontando texto e contexto da publicidade comercial e de prevenção. In: Almeida, Tavares L. et al. (Org.). Drogas: tempos, lugares e olhares sobre seu consumo. Salvador: Edufba. 2004.

VIEIRA, Letícia B. et al.

Abuso de álcool e drogas e violência contra as mulheres: denúncias de vividos. Revista Brasileira de Enfermagem, v.67, n.3, p.366-372. 2014.

WAKEFIELF, Melanie et al.

The cigarette pack as image: new evidence from tobacco industry documents. Tobacco Control, v.11, supl.1, p.i73-i80. 2002.

WHO.

World Health Organization. Global status report on alcohol and health. Genebra: WHO. 2014. 
WHO.

World Health Organization. WHO report on the global tobacco epidemic. Genebra: WHO. 2008.

WYNDER, Ernest L.; GRAHAM, Evarts A.; CRONINGER, Adele B.

Experimental production of carcinoma with cigarette Tar. Cancer Research, v.13, n.12, p.855864. 1953.
YARAK, Aretha.

Consumo frequente de álcool cresceu 20\% nos últimos seis anos. Veja. Disponível em: <http:// veja.abril.com.br/noticia/saude/consumofrequente-de-alcool-aumentou-20-nos-ultimosseis-anos>. Acesso em: 29 jan. 2015. 10 abr. 2013.

ZINBERG, Norman E.

Drug, set and setting: the basis for controlled intoxicant use. New Haven, CO: Yale University Press. 1984. 